\title{
A DESTRUiÇÃO DA NATUREZA E OS ARAUTOS DO CONSERVACIONISMO BRASILEIRO NAS PRIMEIRAS DÉCADAS DO SÉCULO XX
}

\section{Resumo:}

Este trabalho tem como objetivo apresentar um panorama da destruição da natureza no Brasil das primeiras décadas do século XX e os expoentes do conservacionismo brasileiro que se colocaram contra tal quadro de incúria, ignorância e omissão. O papel e as ações dos principais arautos da luta contra a destruição que se infringia ao mundo natural são analisados, destacando-se a atualidade de seus posicionamentos. São apontadas, além disso, as primeiras medidas legais de conservação da natureza no século passado.

Palavras-chave: Conservacionismo, Destruição da Natureza, Brasil, Florestas, Século XX.

\section{Os primórdios da República}

"Temos sido um agente geológico nefasto e um elemento de antagonismo terrivelmente bárbaro da própria natureza que nos rodeia"

(Euclides da Cunha, 1907).

Nos últimos anos do século XIX, com a escravatura abolida e com o novo governo republicano, o contexto econômico do Brasil mantinha-se apoiado na atividade agrícola com vistas à exportação, sendo o café a principal riqueza nacional. Afluía ao país grande contingente de imigrantes estrangeiros, que vinha substituir a mãode-obra escrava. A atividade industrial ainda era incipiente, constituindo a expansão das áreas de cultivo e das ferrovias a principal responsável pela devastação da natureza, principalmente na região sudeste do país.

*Arquiteta, graduada em Saúde Pública pela Faculdade de Saúde Pública - USP, mestre e doutora em Ciências da Engenharia Ambiental pela Escola de Engenharia de São Carlos, USP. Professora das disciplinas de "Estudos Ambientais" e "Projeto Paisagístico" do Curso de Arquitetura e Urbanismo do Centro Universitário de Araraquara - Uniara. E-mail: mfsantos05@ hotmail.com 
A Constituição Federal de 1891 não fez menção às florestas em seu texto, transferindo para os Estados o poder de legislar sobre as terras ditas devolutas, $\mathrm{o}$ que gerou uma profusão de leis e regulamentos estaduais, conflitando com as esferas dos direitos civil e penal. Isto culminou em uma aplicação do direito de propriedade de forma irrestrita, com fazendeiros e madeireiros derrubando e queimando matas indiscriminadamente, corrompendo-se no processo de grilagem de terras públicas ou tomando-as dos pequenos proprietários por meios violentos, práticas largamente difundidas desde o Império e que se acentuariam a partir de então, deixando consequências que seriam perceptíveis na acelerada destruição do mundo natural. Assim comenta Osny Duarte Pereira sobre a questão florestal ao advento da República:

"O período republicano registra a mais vasta destruição florestal de todos os tempos, com o aperfeiçoamento da máquina, a inversão de capitais em larga escala, com utilização até de estradas de ferro particularmente, de guinchos possantes colocados em plena mata, que arrancam as árvores mais frondosas, com a facilidade com que seria extraída do chão uma hortaliça qualquer, arrastadas depois por cabos de aço, até o leito da via férrea." (PEREIRA, 1950, p.108).

Em 1892 o governo republicano, visando cumprir a determinação do Artigo $3^{\circ}$ da Constituição Federal relativo à área no Planalto Central a ser reservada para a instalação da nova capital da União, incumbiu o diretor do Observatório Astronômico e lente catedrático de astronomia e geodésia da Escola Superior de Guerra, Luiz Cruls, de chefiar uma expedição com a finalidade de demarcar o local adequado, considerando como referência o ponto de encontro das cabeceiras dos rios Tocantins, São Francisco e Paraná. Tal determinação constitucional baseava-se em argumentações anteriores sobre as conveniências de se instalar uma nova capital no Planalto Central do país, que remontavam ao início do século XIX.

Em relatório da Comissão Exploradora do Planalto Central apresentado ao Ministro da Indústria, Viação e Obras Públicas em 1894, constavam as observações e os resultados da expedição, consistindo basicamente no levantamento das características topográficas, hidrográficas, fitogeográficas e climáticas da área escolhida para a demarcação.

Um dos astrônomos da expedição, Henrique Morize, observara, em seu trajeto por Goiás, a devastação das matas para a abertura de terras à agricultura, comentando:

"A zona (...), que formava nosso centro de operações (...), possui boas terras, em que crescem com abundância todos os cereais, mas que são cultivadas pelos processos mais rudimentares. As matas vão desaparecendo rapidamente em todo Estado de Goiás, devido ao sistema das queimadas e apenas resiste a vegetação em torno dos rios e ribeirões cuja umidade a protege contra o incêndio." (apud

REVISTA UNIARA, $n .^{0} 21 / 22,2008 / 2009$
CRULS, 1947, p.72).

As técnicas agrícolas rudimentares e a decorrente devastação da natureza, que foram observadas pelo astrônomo da Comissão Exploradora em seu percurso pelo Estado de Goiás, eram comuns pelo país afora, onde quer que a agricultura nômade se instalasse. Euclides da Cunha (1866-1909) falou em suas obras desse furor intrépido pela derrubada, do antigo costume indígena da queimada, ou coivara, exacerbadamente adotado pelo agricultor brasileiro, das mudanças climáticas em locais de frágil equilíbrio natural. Descreveu os tristes cenários resultantes, como o interior paulista, em sua obra "Fazedores de deserto", de 1907:

"...quadro lastimável descortinado pelos que se aventuram, nestes dias, a uma viagem no interior - varando a monotonia dos campos mal debruados de estreitas faixas de matas, ou pelos carreadores longos dos cafezais requeimados, desatandose indefinidos para todos os rumos - miríades de esgalhos estonados, quase sem folhas ou em varas, dando em certos trechos, às paisagens, um tom pardacento e uniforme de estepe..." (CUNHA, 1975, p.186).

A região do vale do Paraíba foi também objeto de sua aguda observação, tendo escrito a respeito "Entre ruínas", publicado em 1907, em que narrou a transformação do vale - das "bordas pinturescas do Paraíba", em que se vislumbravam "matas exuberando floração ridente" - em tristes "ermos desolados". O cenário de morros escalvados, onde se espalhavam as macegas pelos barrancos erodidos, exibindo "a rígida ossamenta de pedra desvendada", denunciava os estragos resultantes da derrubada das matas e a subseqüente ação das intempéries sobre solos esgotados pela rudimentar cultura cafeeira. A pobreza de sua população completava o quadro da natureza arruinada pelos séculos de desastroso manejo.

Em sua famosa obra "Os sertões", publicada pela primeira vez em 1902, Euclides da Cunha apresentou o problema do Nordeste como uma soma de fatores levando a um processo de desertificação daquelas paragens:

"Colaborando com os elementos meteorológicos, (...) com a sucção dos estratos, com as canículas, com a erosão eólica, com as tempestades subitâneas - o homem fez-se uma componente nefasta entre as forças daquele clima demolidor. Se o não criou, transmudou-o, agravando-o. Deu um auxiliar à degradação das tormentas, $\mathrm{o}$ machado do caatingueiro; um supletivo à insolação, a queimada. Fez, talvez, o deserto." (CUNHA, 1984, p.78).

Pouco tempo antes, o geógrafo francês Elisée Reclus (1830-1904) havia relatado suas impressões sobre o desperdício de recursos florestais que testemunhou quando esteve no Brasil por volta de 1900, tendo escrito um livro sobre os aspectos geográficos, etnográficos e estatísticos do país, intitulado "Estados Unidos do Brasil". As florestas brasileiras eram devastadas de maneira imprevidente, conforme observou:

A destruição da natureza e os arautos.. 
"Atacam-na a machado e a fogo, porque as melhores terras são as da mata mais alta e mais densa, e os lavradores têm pressa de substituir por cafezais essas essências florestais que teriam imenso valor em qualquer outro país. Em muitos lugares, houve demasiada pressa em derrubar a mata: os terrenos mal desbravados foram abandonados depois de uma cultura ligeira e uma floresta nova, composta de outras espécies, cresce no lugar da selva primitiva: é a 'capoeira', menos bela, menos pitoresca que a mata virgem, porém mais difícil de percorrer." (RECLUS, 1900, p.310).

Apesar da omissão governamental na esfera federal no tocante à elaboração de leis que coibissem os abusos contra a natureza no Brasil, uma iniciativa pioneira ocorreu no Estado do Rio Grande do Sul, com a promulgação pelo governo estadual da lei n. ${ }^{\circ} 28$ de 5 de outubro de 1899, que continha as disposições sobre o regime florestal no Estado, tratando das terras públicas, regulamentando as terras devolutas para a colonização e para a proteção das florestas, instituindo prêmios às iniciativas de reflorestamento. Em São Paulo foi criado naquele mesmo ano o Serviço Agronômico do Estado, com o objetivo de fazer melhoramentos nos métodos empregados na agricultura e incrementar a produção agrícola.

O pensamento conservacionista no Brasil avançou nos primeiros anos da República no sentido de se estabelecer enquanto aspiração de setores mais esclarecidos da sociedade, devido em grande parte ao trabalho do botânico sueco Alberto Löefgren (1854-1918). Tendo chegado ao Brasil em 1874 com a expedição de André Regnell, patrocinada pela Academia de Ciências de Estocolmo, Löefgren enamorou-se da natureza brasílica e aqui se estabeleceu, dando inúmeras contribuições à difusão da idéia de conservação da natureza e à criação de mecanismos de controle do patrimônio florestal do país.

Designado por Orville Derby para as Seções de Meteorologia e Botânica da Comissão Geográfica e Geológica do Estado de São Paulo, Löefgren organizou o Serviço de Meteorologia do Estado, tendo publicado assiduamente, durante muitos anos, boletins sobre dados climáticos do Estado de São Paulo.

Em relatório sobre os levantamentos realizados pela Comissão em diversos pontos do Estado, Löefgren descreveu os campos do Ribeirão do Feijão, nas proximidades de São Carlos do Pinhal, concluindo ser a vegetação mais variada que a da região de Itapetininga, que visitara anteriormente, comentando:

"Em São Carlos do Pinhal, (...) os terrenos sejam talvez mais bonitos que em Itapetininga, porque além de haver mais cerrados e capões, que quebram a monotonia de uma campina infinda, parece-me haver mais diversidade no colorido da vegetação." (COMISSÃO GEOGRÁFICA E GEOLÓGICADO ESTADO DE SÃO PAULO, 1889, p.47).

REVISTA UNIARA, $n .^{0}$ 21/22, 2008/2009
Atribuiu a esterilidade aparente dos terrenos às queimadas anuais que ocorriam entre Rio Claro e São Carlos, destruindo parte considerável da vegetação que o interessara.

Em 1896, com a sua colaboração, a Seção Botânica da Comissão foi instalada na Serra da Cantareira nos moldes de um horto botânico, tornando-se a primeira reserva florestal do Estado, cujo objetivo era preservar as nascentes de mananciais da cidade de São Paulo. A Seção Botânica dirigida por Löefgren foi transformada em Serviço Florestal e Botânico em 1899, assumindo, a partir de então, "a conservação das florestas, melhor exploração e reflorestamento" do Estado. Dinâmico e arrojado, o botânico sueco conseguiu angariar a simpatia da classe média urbana para a causa da conservação dos recursos florestais. Em 1901, apresentou ao governo estadual um projeto em que sugeria a regulamentação da exploração e a proteção das florestas com a criação de um serviço florestal, porém não conseguiu que sua proposta fosse acatada pelo legislativo.

Em suas excursões ao Nordeste do Brasil como botânico da Inspetoria de Obras contra a Seca, órgão atrelado ao Ministério de Viação e Obras Públicas, Löefgren pôde constatar in loco a incúria e a ignorância no manejo dos recursos naturais naquela região, assolada por secas e penúrias que resultavam da combinação de um clima frágil e da devastação da cobertura vegetal durante séculos. Verificou vestígios de flora mais rica, de antigas florestas em vários lugares do Ceará, Paraíba, Pernambuco e Bahia, dentro da área que estudou como região das secas, onde se incluíam também os Estados do Piauí e Rio Grande do Norte. Até os campos de gramíneas, que poderiam ser armazenadas para servir de forragem ao gado, eram constantemente queimados ou deixados para que se queimassem indefinidamente por dias a fio, com suas chamas avivadas pelos ventos invadindo as matas e as caatingas. Cursos d'água, que haviam sido perenes, enchiam durante um episódio de chuva e escoavam rapidamente, perdendo-se a água, tão necessária, por não ser armazenada para usos futuros.

Löefgren investigou particularmente as causas do desaparecimento da flora na região que estudou, tendo levantado evidências da exuberância da vegetação mediante relatos de moradores, na bibliografia antiga sobre os locais ou por ter constatado empiricamente a presença de relictos da flora nativa:

"...a flora (...) atualmente se acha em constante diminuição, devido principalmente à devastação progressiva pelos cortes incessantes e ruinosos, pelos descuidos com o fogo nas ocasiões das queimas e pela avultada criação de cabras, sem método e numa liberdade desastrosa para a vegetação, sendo esta criação assim um dos maiores impedimentos para uma renovação espontânea das essências arbustivas e arborescentes e, portanto, florestais." (LÖEFGREN, 1923, p.55).

A destruição da natureza e os arautos... 
Baseando-se em dados oficiais sobre a região estudada, Löefgren verificou que $31 \%$ da área considerada haviam possuído cobertura florestal em tempos passados, restando apenas $8 \%$ de área florestada à época de seu estudo, em 1912. O Estado do Ceará se destacava, pois outrora as florestas haviam coberto $43 \%$ de seu território, apenas restando $15 \%$ de florestas remanescentes quando Löefgren lá esteve (LÖEFGREN, 1923, p.107). Em uma viagem realizada dois anos antes para aquele Estado, já havia comentado a respeito do processo de devastação em curso:

"Das matas primitivas o Estado do Ceará tem pouco conservado e a transformação delas em capoeiras progride de um modo assustador devido a causas inteiramente artificiais, das quais a ignorância do seu valor ocupa evidentemente o primeiro lugar (...). Deve-se esta devastação, principalmente, ao sistema de lavoura que, para plantar, derruba e queima, para, após as colheitas, abandonar aquele terreno e continuar a derrubada mais adiante." (LÖEFGREN, 1982, p.68).

Até mesmo a lenha para as atividades cotidianas estava cada vez mais rara nas localidades por onde passou o botânico, tendo verificado o hábito das populações locais de construir cercas de galhos finos colocados lado a lado ${ }^{1}$. Achava curioso os habitantes não construírem muros, mais duráveis e resistentes, com as pedras soltas em abundância, como o grés branco que usavam em alguns lugares para construir as moradias. Löefgren criticou o que considerava um costume perdulário na utilização da vegetação da caatinga, sobre o que afirmou:

"O desbaste demasiado e a devastação das caatingas é ainda mais grave do que as próprias matas e como ocupam, de preferência, as chapadas e outros terrenos planos, a ação do vento, aí, une-se aos outros fatores desfavoráveis para desiludir completamente sobre a possibilidade de uma renovação espontânea da vegetação desaparecida naquelas extensões." (LÖEFGREN, 1982, p.109)

O reflorestamento da região foi proposto por Löefgren, que chegara à conclusão de que havia condições fisiográficas e metereológicas para a empreitada, assumida pela Inspetoria de Obras contra a Seca, primeiramente por meio da criação de hortos florestais - um em Quixadá, no Estado do Ceará e outro em Joazeiro, no Estado da Bahia - para a produção de mudas de espécies vegetais, cuja adequabilidade ao reflorestamento seria verificada através de plantios experimentais.

A questão do reflorestamento foi uma das bandeiras que Löefgren assumiu, dentre aquelas que defendeu na sua luta pela conservação da natureza no Brasil. Por sugestão sua, o governo adquiriu as terras de Itatiaia em 1908, que viriam formar o primeiro parque nacional do país em 1937 (cf. BARROS, 1952, p.38). Propôs que

'Esse hábito perdura até os dias de hoje, como pode ser verificado em (CÂMARA; COIMBRA-FILHO, 1996, p.53).

REVISTA UNIARA, $n .^{0} 21 / 22,2008 / 2009$ se transformassem em reserva as terras devolutas do Pontal do Paranapanema, no Estado de São Paulo. Além disso, foi idéia sua a criação do "Dia da Árvore", comemorado pela primeira vez em 1902, na cidade paulista de Araras.

Outros cientistas no começo do século XX manifestaram sua preocupação com o ritmo da devastação florestal no Brasil, dentre eles se sobressaindo o zoólogo alemão Hermann von Thering (1850-1930), que foi diretor do Museu Paulista de 1894 a 1916. Em uma conferência que apresentou em 1911 na Universidade Popular de Piracicaba - depois publicada na Revista do Museu Paulista - Hermann von Ihering mostrou-se indignado com os desmandos e abusos praticados contra a natureza e, em particular, contra as matas do país. Criticou diretamente o congresso federal que havia aprovado no orçamento de 1911 uma premiação para o maior exportador de madeira de lei. "Ao homem que isto fizer não deve caber prêmio em dinheiro mas a cadeia", exclamou o naturalista. Comentou em sua conferência as vantagens da adoção de regime florestal racional que poderia prover o mundo todo com "as melhores e mais belas qualidades de madeira" com o devido reflorestamento, sem o qual se cometeria "um crime contra a riqueza futura e contra o clima do país". Citou o exemplo dos Estados Unidos que, devido aos problemas decorrentes do desmatamento, haviam instituído parques nacionais e criado uma legislação florestal. Assim também a Alemanha, que obtinha grandes benefícios das suas florestas, contrastando com o que acontecia no Brasil, em pleno curso de seu "suicídio econômico".

Dentro de um quadro de irracionalidade no manejo dos recursos florestais, a própria Argentina se abastecia com madeira de lei do Brasil, que não era renovada em seus estoques pela ausência de reflorestamento. Segundo von Ihering, as companhias estrangeiras também contribuíam para a devastação alegando desenvolver projetos de colonização e recebendo, desse modo, autorização do governo para desmatar extensas áreas. Apontou também a questão das terras devolutas como um agravante no processo destrutivo, pois o Estado não impunha fiscalização eficiente, nem tampouco criara mecanismos para coibir as invasões e desmatamentos. Colocou três problemas essenciais que compunham, no seu modo de ver, a questão da conservação das matas:

"O fornecimento de lenha ou combustível; a extração de madeira de lei e outros produtos; a defesa dos mananciais dos rios e ribeirões, no interesse do clima e do abastecimento de água." (IHERING, 1911, p.494).

Propôs, em sua conferência, a criação de serviços de silvicultura nas esferas federal e estadual, enfatizando a importância do reflorestamento em áreas já bastante degradadas, citando o exemplo do Estado de São Paulo que, nos trinta anos anteriores ao discurso de von Ihering, havia sofrido um processo de intenso 
desmatamento para o plantio de café, em que solos esgotados haviam sido abandonados aos "sapezais e samambaias". Defendeu, além disso, que se procurasse manter a peculiaridade da mata brasileira, por sua grande variedade de espécies, ao afirmar:

"Antes de tudo, é preciso conservar o caráter misto e variado das matas brasileiras e limitar a plantação de florestas uniformes de eucaliptos, pinheiros, etc., a poucas essências florestais, particularmente as que servem de combustível." (IHERING, 1911, p.495).

Quanto aos graves problemas enfrentados pela região das secas no Nordeste, von Ihering classificou de "um monumento à inépcia dos governos e estadistas do século passado", que não haviam tido competência para acabar com as derrubadas das matas, ao mesmo tempo em que buscassem reflorestar as áreas desmatadas. Além disso, criticou a indiferença dos governos dos Estados e da União com o desperdício dos recursos florestais do país promovido pela implantação das ferrovias, em que se devastavam grandes áreas não só para a abertura das estradas, mas também para o fornecimento de madeira para os dormentes e para o abastecimento das locomotivas.

Em 1909, Hermann von Ihering doou ao governo do Estado de São Paulo uma reserva florestal localizada no alto da Serra do Mar. No ano seguinte, elaborou um programa para a organização do serviço florestal no Brasil, em que constavam dezesseis itens normativos da conservação e exploração das florestas do país. Porém, em âmbito federal, o Serviço Florestal só seria criado em 1925.

Por outro lado, como cabia às esferas estaduais administrarem as terras públicas, alguns dos Estados adotaram medidas para coibir abusos e controlar a exploração dos recursos florestais. O Estado da Bahia elaborou a primeira lei de terras em 1897 e criou o "Regulamento para a Defesa, Conservação e Aproveitamento das Florestas do Estado" em 1905. Os Estados do Piauí e Pernambuco criaram os seus Serviços Florestais em 1910 e 1916, respectivamente. No Estado do Paraná, o corte da erva-mate já era regulamentado desde 1854, tendo sido fundado o Serviço Florestal do Estado em 1907. O Rio Grande do Sul foi o Estado com a melhor legislação florestal, com a lei n. ${ }^{\circ} 28$ de 5 de outubro de 1899, que regulamentou o uso das terras públicas. O Estado de Santa Catarina, por sua vez, teve o seu Serviço Florestal criado em 1914, enquanto no Estado de Minas Gerais, a conservação das matas e o reflorestamento foram atribuídos à esfera municipal em 1891. O Estado do Rio de Janeiro, muito embora tivesse em seu território a capital da República, apenas adotou medidas de conservação de seu patrimônio florestal em 1925, com um Projeto de Código Rural. (PEREIRA, 1950, p.112-133).

O Estado de São Paulo, depois de haver criado o Serviço Agronômico em 1899,

REVISTA UNIARA, $n .^{0}$ 21/22, 2008/2009 37 instituiu o Serviço Florestal do Estado em 1911. O governo estadual se empenhou em inventariar os recursos naturais, desenvolvendo através da Comissão Geográfica e Geológica do Estado de São Paulo diversas expedições, dentre as quais incluíamse as explorações do Rio Tietê em 1905, do Rio do Peixe em 1907, do Rio Paraná e do Rio Juqueriquerê em 1911, do Rio Ribeira de Iguape em 1914, além dos levantamentos realizados no vale do Rio Paraíba, no litoral e na região sul do Estado.

Simultaneamente ao processo de dilapidação do patrimônio natural que se operava ainda com maior intensidade no começo do século XX, alguns escritores conquistavam a simpatia do público ao discorrer sobre as maravilhas naturais do país, numa época em que setores mais esclarecidos da população começavam a se conscientizar da destruição à sua volta. Foi o caso de Afonso Celso de Assis Figueiredo (1860-1938) que teve seu livro "Por que me ufano de meu país" reeditado diversas vezes após a primeira publicação em 1901, tornando-se um dos maiores sucessos editoriais da época. Em sua descrição da natureza do país o autor buscava expressar sentimentos por ela inspirados, construindo uma narrativa que remetia aos valores difundidos pela estética do sublime:

"Nas matas virgens do Brasil (...) reside um dos espetáculos mais augustos da criação. Sobrelevam o oceano em mistério, em diversidade de panoramas, em excesso de vida, em magnificência que, ao mesmo tempo, acabrunham a inteligência humana e a arrebatam, acentuando-lhe a ideia das forças superiores regedoras do planeta. $E$ a natureza em expansão e liberdade máximas: mares e mares de vegetação prodigiosa, nos quais cada onda representa um mundo de cousas preciosas e lindas; silêncio imponente, ou antes, profundo rumorejo, clamor longínquo, indefinida reunião de harmonias, provocando religiosidade e vago terror; cheiros acres e balsâmicos, em abundantes vagas de aromas que o peito haure com delícia, como se fossem remédio para suas misérias e melancolias." (FIGUEIREDO, 1901, p.35).

A comunidade científica do país mostrava-se cada vez mais preocupada com a destruição das reservas florestais e a sua influência no clima e na saúde pública. $\mathrm{Na}$ primeira reunião do Congresso Brasileiro de Geografia, que ocorreu no Rio de Janeiro em 1909, o médico Ezequiel Correa de Souza Brito reforçou a posição, que já havia defendido em artigo publicado alguns anos antes, contra a devastação das florestas no Brasil (BRITO, 1902), enfatizando a sua importância quanto aos aspectos profiláticos e alertando para os prejuízos decorrentes da devastação florestal.

A proposta de criação de um parque nacional em Itatiaia foi colocada, em dezembro de 1913, pelo naturalista suíço Joseph Hubmayer ao ministrar uma conferência na Sociedade de Geografia do Rio de Janeiro, apoiado por cientistas como o geólogo Orville Derby, o geógrafo e historiador Barão Homem de Mello e o botânico Alberto Löefgren, de quem partira a sugestão ao Ministro da Agricultura, 
Cândido Rodrigues, para a aquisição da área. Em um artigo publicado no "Jornal do Comércio" do Rio de Janeiro, de 22 de dezembro do mesmo ano, Hubmayer defendeu publicamente, através da imprensa, a importância de se transformar a região de Itatiaia em parque nacional:

"O Parque Nacional de Itatiaia, sem igual no mundo, estaria quase às portas desta bela Capital, oferecendo aos cientistas e estudiosos riquíssimos elementos para as suas pesquisas, aos convalescentes pelo trabalho exaustivo nas barulhentas cidades, um retiro ideal para a sua reconstituição física e mental e aos excursionistas e curiosos uma infinidade de atrativos." (apud: BARROS, 1952, p.39).

Outra vez o pensamento conservacionista se anteciparia à ação do Estado, sempre moroso em relação às propostas que implementassem uma política de conservação da natureza no Brasil, pois o Parque Nacional de Itatiaia só seria criado em 1937.

\section{Alberto Torres e o primado da conservação da natureza}

"A civilização humana é produto do sacrifício da Terra ao impulso de cobiças incontidas" (TORRES, 1914).

O pensamento conservacionista no Brasil adquiriu consistência e maior profundidade a partir das idéias de Alberto de Seixas Martins Torres (1865-1917), ensaísta, jurista e político fluminense. Quando estudante na Faculdade de Direito de São Paulo, de 1882 a 1884, envolveu-se na propaganda abolicionista e republicana - em plena efervescência no meio acadêmico - através de participações em jornais, clubes republicanos, conferências e discussões. Após finalizar o seu curso de Direito em Recife, para onde havia se transferido, começou sua carreira profissional na cidade do Rio de Janeiro. Dedicou-se ao jornalismo e à carreira política, engajandose intensamente às causas abolicionista e republicana com a publicação, a partir de meados de 1888, de diversos artigos no jornal republicano "O Povo", de Niterói. A sua ativa inserção no movimento pela proclamação da República tornou-o "um dos construtores do regime republicano, pela ação política e jornalística" (MARSON, 1975, p.503).

A partir do novo regime, Alberto Torres participou da vida pública em diversos cargos e funções. Foi deputado estadual (1892-1893), deputado federal (18941896), Ministro da Justiça (1896-1897), Presidente do Estado do Rio de Janeiro (1897-1900) e Ministro do Supremo Tribunal Federal, cargo em que permaneceu de 1900 a 1909, aposentando-se por motivos de saúde. Voltou-se, então, para o jornalismo, escrevendo sobre assuntos variados no jornal "O País", principalmente sobre sua especialidade, o direito internacional, além de outros temas concernentes

REVISTA UNIARA, $n .^{0} 21 / 22,2008 / 2009$ à política econômica e relações internacionais.

De volta de uma viagem à Europa em 1909, publicou seu primeiro livro, "Vers la paix", em que analisou o pensamento pacifista, ao qual aderira após a leitura de diversos autores europeus e norte-americanos. As questões internacionais, a corrida armamentista e o expansionismo imperialista constituíram a temática de seu segundo livro, "Le problème mondial", de 1913.

Aconservação da natureza passou a fazer parte das cogitações teóricas de Alberto Torres a partir de seus livros "A organização nacional" e "O problema nacional brasileiro", ambos de 1914, que reuniam os artigos que publicara no "Jornal do Commercio" e na "Gazeta de Notícias" a partir de 1910. Em seu último livro "As fontes de vida no Brazil", lançado em 1915, aprofundou a sua análise sobre a questão.

Alberto Torres possuía uma visão estratégica da conservação da natureza, cujas linhas gerais podem ser apreendidas neste excerto de seu livro "O problema nacional brasileiro":

"A civilização tem o dever de conservar as riquezas inexploradas da Terra, destinadas às gerações futuras, e de defender as que estão em produção, contra a exploração imprevidente, assim como a de proteger todas as raças e nacionalidades contra as formas de concorrência que possam importar ameaça a seus interesses vitais, bem como a segurança, propriedade e prosperidade de suas descendências." (TORRES,1914, p.XI).

A conservação da natureza para Alberto Torres consistia em uma das mais importantes ações a serem empreendidas para se estabelecerem as bases sólidas de uma nação, dentro de um processo de organização geral do país nas esferas econômica, político-administrativa, jurídica e social. Indicava haver assimilado idéias fisiocráticas ao defender a aptidão agrícola do país como fator a ser desenvolvido para a harmonia social no futuro, mediante o direito à terra na forma generalizada de pequenas propriedades agrícolas, cuja inspiração parece ter buscado nos princípios da democracia agrária de Thomas Jefferson, de quem era leitor. Colocava a adoção de medidas de conservação no patamar das mais importantes tarefas a serem empreendidas no país:

"O problema do reflorestamento, o da restauração das fontes naturais e o da conservação e distribuição da água são, em nosso país, problemas fundamentais, extraordinários, mais importantes que o da viação comum e muitíssimo mais que o das estradas de ferro." (TORRES, 1915, p.22).

Em sua opinião, as florestas deviam ser conservadas nos "espinhaços das serras", nos pontos mais elevados e, "em geral, em toda a parte", só se permitindo derrubálas para atender à necessidade de terra pela população, que nela deveria praticar a agricultura mediante "processos racionais, intensivos e conservadores" e estar

A destruição da natureza e os arautos... 
atenta às decorrências climáticas da eliminação da cobertura florestal e da alteração do ciclo hidrológico.

Criticava de forma veemente as práticas rudimentares e irracionais que eram utilizadas no campo, levando ao esgotamento do solo e ao abandono da terra, produzindo-se às custas da dilapidação dos recursos naturais, conforme observou:

"Todas as aparências do nosso progresso e da nossa civilização não representam mais do que frutos da audácia na intensa exploração extensiva de nossas riquezas." (TORRES, 1933, p.242).

As ferrovias eram vistas por Alberto Torres com bastante reserva, pois não considerava que, em países novos como o Brasil, elas promovessem a circulação e a distribuição econômica. Ao contrário, estimulavam a exploração extensiva, colaborando para a "obra de ruína" da natureza iniciada nos tempos da Colônia. A propósito da exploração desenfreada dos recursos naturais do país com a participação de grupos internacionais, comentou:

"O nosso sistema hidrográfico, tão desigual e ingratamente distribuído, tão mal estudado e brutalmente desperdiçado, sem nenhum regime de canalização e de irrigação; as nossas florestas, tão levianamente devastadas nesse afã de ir estendendo populações aventureiras e empresas capitalistas, que lastram como pragas devastadoras, por todo o território - sem amor pela terra nem interesse pelo futuro humano - estão a pedir uma política de conservação da natureza, de reparação das regiões estragadas, de concentração das populações nas zonas já abertas à cultura, sendo educado o homem para aproveitá-las e para as fazer frutificar, valorizando-as." (TORRES, 1914, p.104, grifo nosso).

Alberto Torres colocou a problemática da conservação da natureza no centro da política que deveria ser desenvolvida no Brasil. Posicionava-se contra a prioridade máxima dada pelo governo e pela sociedade da época às exportações, argumentando que estas constituíam "fontes de fortuna pessoal" pela manipulação financeira dos lucros com os excedentes da produção, atraindo a mão-de-obra para a monocultura em detrimento da produção para o consumo interno e das culturas básicas para a nutrição, que dariam segurança e prosperidade à população de forma generalizada. Além disso, as exportações estimulavam a lavoura extensiva e predatória, sem haver consideração com o esgotamento dos recursos naturais, em atitude irresponsávele indiferente com as futuras gerações.

Em sua proposta de revisão à Constituição Federal de 1891, Alberto Torres incluiu o parágrafo $10 .^{\circ}$ do Artigo 60, das atribuições do Conselho Nacional, órgão permanente de fiscalização das ações do governo federal, ao qual cumpriria:

"Promover a defesa do solo e das riquezas naturais do país, propondo as medidas necessárias para preservar as fontes de riqueza ainda virgens e para assegurar a

REVISTA UNIARA, $n .^{0} 21 / 22,2008 / 2009$ conveniente exploração, conservação e reparação das que estiverem sendo exploradas." (TORRES, 1933, p.493).

Houve modesta repercussão das idéias de Alberto Torres nos meios intelectuais e nenhuma nos meios políticos, não obstante tenham sido elevadas ao status de verdadeira doutrina para alguns, na maioria escritores e cientistas, que viam o autor quase sob uma aura messiânica. Em 10 de novembro de 1932, foi fundada no Rio de Janeiro a "Sociedade dos Amigos de Alberto Torres", estando entre os sócios admiradores da obra do pensador fluminense o antropólogo Edgar Roquette-Pinto e o botânico Alberto José de Sampaio, importantes e renomados pesquisadores do Museu Nacional. Entre os objetivos da Sociedade - que se manteve em atividade até 1939 - estavam a discussão e divulgação de sua obra.

Alberto Torres posicionou-se de modo atípico no contexto político e econômico do período, desafiando os cânones econômicos então vigentes. Suas propostas eram impregnadas de grandes doses do altruísmo bem ao gosto positivista da época, mas dotadas de sentido frente ao quadro de devastação da natureza e da desorganização social e econômica do país, que gerava desigualdades e injustiças, mesmo que se façam restrições a algumas de suas ideias e se perceba o anacronismo de outras. Demonstrou compreender o Brasil ao declarar:

"O valor de um país feito com a criação de fortunas, nunca atingirá a importância do valor formado com a generalização da riqueza." (TORRES, 1933, p.185).

Alberto Torres teve, portanto, papel importante na história do conservacionismo brasileiro do século XX, influenciando a geração de conservacionistas que o sucedeu.

\section{Alberto José de Sampaio e a primeira conferência brasileira de proteção à natureza}

Em 1905, um jovem botânico fluminense, Alberto José de Sampaio (1881-1946), ingressou nos quadros do Museu Nacional como assistente de botânica. Tendo se tornado professor chefe em 1912, já naquela época Sampaio demonstrou seu interesse pelas questões relativas ao reflorestamento e à formação de reservas de florestas nativas remanescentes ao publicar um artigo no periódico "Chácaras e Quintais" sobre esses temas. Porém, seria a partir de 1926 que Sampaio passaria a refletir de modo mais intenso sobre o problema florestal, com a publicação de um relatório que apresentara ao "Congresso Internacional de Silvicultura" em Roma, ocorrido em março daquele ano. Constavam do documento descrições detalhadas das florestas brasileiras e suas possibilidades de aproveitamento econômico. Os dados sobre as áreas florestais do país, Sampaio os retirou do mapa florestal de Gonzaga de Campos (BRASIL, 1912), que era a referência fundamental sobre o assunto à época. 
Sampaio mencionou em seu relatório as reservas florestais que haviam sido instituídas até aquela data pelo governo brasileiro (cf. SAMPAIO, 1926, p.114), dentre as quais, a Reserva da Serra de Itatiaia, aos cuidados do Jardim Botânico do Rio de Janeiro, a Reserva das "Matas da Tijuca", para a proteção das nascentes dos mananciais do Rio de Janeiro, a Reserva Florestal do Território do Acre, que totalizava 30.400 quilômetros quadrados e que havia sido criada em 1911 e a Estação Biológica do Alto da Serra em São Paulo, sob os cuidados do Museu Paulista e doadas ao Estado pelo seu ex-diretor, Hermann von Ihering.

Em palestra proferida na Escola Politécnica em 25 de maio de 1927, Sampaio reforçou os argumentos utilizados em seu relatório anterior, particularmente quanto à sua preocupação como botânico pela destruição dos "grandes viveiros de espécies raras", antes comuns nas florestas, observando a tendência de homogeneização imposta à natureza pelo homem e a resultante formação de paisagens monótonas. Citou a propósito Vidal de la Blache, o qual atinara para "a obra geral da uniformização se não de todo o planeta, pelo menos de cada uma das zonas no planeta". (apud: SAMPAIO, 1928, p.18) Em sua explanação ressaltou que, do ponto de vista utilitário, econômico e industrial, as florestas homogêneas, simplificadas e uniformizadas eram as mais indicadas, fazendo-se necessário, porém, a conservação de áreas de florestas nativas.

Como botânico do Museu Nacional, Sampaio fez parte da Expedição de Demarcação de Fronteiras Óbidos-Tumucumaque, entre setembro de 1928 e janeiro de 1929, comandada pelo General Rondon e tendo por companhia o escritor Gastão Cruls, que o mencionou em seu livro "A Amazônia que eu vi" (CRULS, 1938), relato de mais uma das viagens da "Comissão Rondon".

Ao participar do "Congresso Internacional de Geografia", ocorrido em Paris em 1931, Sampaio teve contato com organizações internacionais de proteção à natureza² . Ao voltar para o Brasil passou a se dedicar ao tema, correspondendo-se com o "Office Internationale pour la Protection de la Nature", entidade fundada em 1930 e com sede em Bruxelas, cuja manutenção vinha de diversas instituições científicas internacionais.

Desenvolveu, então, um processo de divulgação dos fundamentos da proteção da natureza (terminologia que adotaria) entre o público brasileiro, proferindo inúmeras palestras em entidades civis e escolas, paralelamente às suas atividades no Museu Nacional, onde ministrou, de forma pioneira, a "Biogeografia Dinâmica", disciplina

${ }^{2}$ Alberto José de Sampaio utilizou-se da terminologia mais usada internacionalmente em sua época, ou seja, proteção, em vez de conservação. Este último termo seria adotado posteriormente por ter sentido mais amplo e dinâmico, conforme CARVALHO (1966, p.1)

REVISTA UNIARA, $n .^{0} 21 / 22,2008 / 2009$ cujo conteúdo se aproximava do enfoque ecológico e na qual inseriu a nova abordagem.

Sampaio e outros cientistas do Museu Nacional haviam iniciado, a partir da primeira década do século XX, um processo de revitalização daquela instituição que na década de 30 mostrava sua plenitude em termos de produção científica e engajamento com a sociedade da época, promovendo inúmeros eventos de cunho didático e cultural.

A inserção da proteção da natureza no âmbito do ensino fundamental e técnico foi priorizada por Sampaio, além de ter apoiado a criação de associações e grupos, como os "Clubes de Amigos da Natureza" nas escolas municipais do Rio de Janeiro e a "Sociedade dos Amigos das Árvores", fundada naquela cidade em 1931.

Em artigo publicado em 1..$^{\circ}$ de março de 1931 no "Jornal do Commercio", Sampaio analisou os objetivos e a importância dos parques nacionais no mundo e no Brasil. Ateve-se à questão da defesa das florestas brasileiras, mencionando o exemplo da Itália com a "Milicia Forestale Italiana", em que o serviço florestal era militarizado. Para o Brasil sugeriu que fosse adotada uma atuação mista civil-militar na solução do problema defensivo das florestas.

Em pleno governo de Getúlio Vargas, as idéias de Sampaio imbuíram-se da convicção no papel fundamental do Estado no controle das ações sobre a natureza. Como um dos membros fundadores da "Sociedade Amigos de Alberto Torres", Sampaio expandiu a sua participação no trabalho de difusão das idéias do pensador fluminense, em especial sua abordagem com relação aos recursos naturais, por meio da imprensa falada e escrita.

A "Primeira Conferência Brasileira de Proteção à Natureza", realizada no Rio de Janeiro de 8 a 15 de abril de 1934, foi organizada pela "Sociedade dos Amigos das Árvores", por sugestão de Alberto José de Sampaio. O Presidente Getúlio Vargas deu pessoalmente seu apoio à organização do evento e determinou que toda a correspondência da Conferência destinada a órgãos públicos fosse encaminhada pela Secretaria do Palácio do Catete no Rio de Janeiro.

Da comissão organizadora e do conselho técnico da Conferência participaram diversos intelectuais e cientistas sintonizados com o tema, como Edgar RoquettePinto, então diretor do Museu Nacional, Armando Magalhães Corrêa, da Escola Superior de Belas Artes, Paulo Ferreira de Souza, do Ministério da Agricultura, Francisco Iglesias, ex-diretor do Serviço Florestal do Brasil, João Geraldo Kuhlmann, do Instituto Biológico, o próprio Alberto José de Sampaio e outros.

Durante uma semana reuniram-se representantes do mundo acadêmico do país e do exterior para apresentarem seus trabalhos sobre a proteção da natureza no âmbito de sete seções: educação, proteção à natureza em geral, solo e sub-solo, flora, fauna, antropologia e biogeografia (hábitat rural), legislação e métodos.

Na sessão inaugural do evento, nas dependências do Museu Nacional, foram lidas 
poesias às árvores e tocou-se a sinfonia "O Guarani", de Carlos Gomes como prólogo ao discurso de abertura do presidente da "Sociedade dos Amigos das Árvores", Leoncio Corrêa. Buscava-se a união da ciência à poesia, como conclamara Humboldt, pois entre os trabalhos podiam ser encontrados de longas odes às árvores a trabalhos científicos relativos à proteção da natureza. Os assuntos abordados foram os mais diversos, tais como, a necessidade de se criarem parques nacionais no Brasil, os problemas acarretados pela devastação das florestas, questões relativas ao reflorestamento no país, aspectos da proteção da natureza em países como aAlemanha, Itália e Estados Unidos, legislação protecionista brasileira e internacional, entre outros.

Dentre os participantes destacou-se o Dr. Hugo Salomon, presidente da "Comisión Nacional Argentina de Protección a la Fauna Sudamericana", que viria a se tornar internacionalmente conhecido como o pioneiro da proteção da natureza na América do Sul. No trabalho que apresentou à Conferência, Dr. Salomon afirmou ser "a conservação da fauna de um país (...) intimamente ligada à proteção das selvas"3. Outra contribuição da Argentina consistiu no trabalho de José Liebermann, do Jardim Zoológico de Buenos Aires, sobre a proteção da natureza naquele país, que já possuía um parque nacional, antecipando-se ao Brasil.

O evento foi encerrado com uma excursão à Ilha de Paquetá, no Rio de Janeiro e como relator-geral da Conferência, Alberto José de Sampaio apresentou posteriormente os resumos e comentários de diversos trabalhos, munindo-se de dados e informações que acrescentaria ao seu livro "Biogeografia dinâmica. A natureza e o homem no Brasil. Noções gerais e estudo especial da proteção da natureza no Brasil", publicado em 1935 e repleto de referências à "Primeira Conferência Brasileira de Proteção à Natureza". Nesse trabalho, Sampaio apresentou justificativas não só científicas como também éticas e estéticas para a proteção da natureza, enriquecendo suas páginas com muitas poesias e trechos de textos alusivos às virtudes do mundo natural. À linguagem científica acrescentou a linguagem literária e pretendeu que, "juntas e harmônicas", apontassem na natureza suas "belezas e utilidades".

Alberto José de Sampaio, que se tornou diretor do Museu Nacional, continuou acreditando na necessidade de se incutir nas novas gerações a "mentalidade reflorestadora" (SAMPAIO, 1933, p.46) de que falara Monteiro Lobato em 1920, mas mudou a visão estritamente ligada às possibilidades econômicas das florestas brasileiras, que demonstrara na juventude. Passou a perceber um sentido na conservação da natureza que transcendia suas antigas convicções, levandoo a afirmar: "precisamos ter florestas, defender florestas, pela simples razão de

\footnotetext{
${ }^{3}$ Parecer sobre o trabalho apresentado pelo Dr. Hugo Salomon. (SAMPAIO, 1935a, p.77).
}

que são belas em sua majestade (...) Não simplesmente por pão." (apud DEAN, 1997, p.27)

\section{Conclusão}

Durante o governo de Getúlio Vargas, a partir de 1930, a conservação da natureza no Brasil passou a ser vista sob um ponto de vista estratégico, em que o Estado considerou os recursos naturais sob sua tutela visando constituir reservas florestais e minerais e controlar os recursos hídricos. Em 1933, o Decreto $n^{\circ} 22.698$ regulamentou as expedições ou missões particulares, nacionais ou estrangeiras, no território nacional. Foram estabelecidas diversas regulamentações relativas aos recursos naturais do país - destacando-se o Código Florestal, criado pelo Decreto n ${ }^{\circ} 23.793$ de 23 de janeiro de 1934, o Código de Minas, através do Decreto n 23.642 e o Código das Águas, pelo Decreto $\mathrm{n}^{\circ} 24.643$, ambos assinados em 10 de julho de 1934. Esses Códigos se apoiavam em uma nova postura sobre o direito de propriedade estabelecida pela Constituição Federal promulgada no mesmo ano.

Especificamente quanto às florestas, as falhas do Código Florestal e a falta de condições do Estado para fazer cumpri-lo acabaram por não coibir a continuidade e o aumento da devastação florestal.

Em todas as partes do país onde as fronteiras agrícolas avançaram, o método de derrubada-queimada continuou sendo o mais utilizado, chegando a representar em alguns Estados uma ameaça aos últimos resquícios de floresta. Foi o caso de Pernambuco, como atestaram os estudos de Vasconcellos Sobrinho, da Seção Botânica do Instituto de Pesquisas Agronômicas da Escola Superior de Agricultura daquele Estado. Para desenvolver suas pesquisas, foi necessário se deslocar para algumas propriedades ao sul do Estado, o que o levou a declarar: "As matas de Pernambuco, outrora muito pujantes, estão hoje reduzidas a capoeirões de escasso valor". (VASCONCELLOS SOBRINHO, 1937, p.3).

Esse era o cenário de devastação das primeiras décadas do século XX, contra o qual se insurgiram os conservacionistas mencionados e outros que também merecem destaque como o deputado federal Antonio Augusto de Lima (1859-1934), o escritor Henrique Maximiano Coelho Neto (1864-1934) e o médico José Marianno Filho (1881-1946).

Não obstante haver passado várias décadas dos fatos aqui relatados, o que vemos atualmente é um agravamento da destruição da natureza no Brasil pela expansão da ocupação de regiões que nem eram cogitadas na época abordada pelo presente trabalho, como a Amazônia. A situação é imensamente mais grave, considerando-se que os meios de destruição são muito mais eficientes e rápidos. Além disso, a conivência governamental e a ausência de figuras públicas, cujas vozes discordantes se façam ouvir, - e tenham capacidade de mobilizar a sociedade 
brasileira, - agravam ainda mais o atual quadro de incúria e furor dendrocida.

São, portanto, extremamente oportunas e dignas de reflexão as palavras do escritor Coelho Neto em seu discurso em defesa das florestas brasileiras pronunciado na Câmara Federal dos Deputados, em 6 de setembro de 1911:

"Nós que somos o povo do deixa andar, que nos embalamos nos braços da Providência, que só nos preocupamos com o sol que brilha sem nos lembrarmos da noite vindoura; nós que vivemos de esperanças, alardeando jatanciosos que possuímos uma natureza incomparável, que a nossa terra é um manancial perene; nós infelizmente já começamos a sentir que o manancial esgota-se e já nos levantamos para esperar, de pé, a miséria que se anuncia." (COELHO NETO, H.M., 1911. A defesa das florestas. apud: PEREIRA, 1950, p. 531).

\section{Referências bibliográficas:}

BARROS, Wanderbilt Duarte de. Parques Nacionais do Brasil. Rio de Janeiro: Ministério daAgricultura, 1952. (Série Documentária, 1).

BRASIL, Ministério da Agricultura, Indústria e Comércio. Mappa Florestal. Rio de Janeiro:Serviço Geológico e Mineralógico do Brasil, 1912.

BRITO, Ezequiel Correa de Souza. Adevastação das florestas. Revista Médica de São Paulo, n.5, p.25-31, 1902.

CÂMARA, Ibsen de Gusmão; COIMBRA-FILHO, Adelmar F. Os limites originais do bioma MataAtlântica na Região Nordeste do Brasil. Rio de Janeiro: Fundação Brasileira para a Conservação da Natureza, 1996.

CARVALHO, José Cândido de Melo. A conservação da natureza e recursos naturais na Amazônia Brasileira. Rio de Janeiro: Fundação Brasileira para a Conservação da Natureza, v.7, p.1-47,1966. (Separata).

COMISSÃO GEOGRÁFICAE GEOLÓGICADOESTADO DE SÃO PAULO. Relatório. São Paulo: Typographia Jorge Seckler \& Cia., 1889.

CRULS, Gastão. AAmazonia que eu vi. Obidos - Tumucumaque. SãoPaulo: Nacional, 1938. (Brasiliana, 113).

CRULS, Luiz. Relatório da Comissão Exploradora do Planalto Central do Brasil.
São Paulo: Nacional, 1947. (Brasiliana, 258).

CUNHA, Euclydes da. Contrastes e confrontos. Rio de Janeiro, Record, 1975.

. Os sertões. São Paulo:Três Livrose Fascículos, 1984. (Biblioteca do Estudante-Obras imortais da nossa literatura).

DEAN, Warren. Aferro e fogo.A história e a devastação da Mata Atlântica brasileira. São Paulo: Companhia das Letras, 1997.

FIGUEIREDO,Afonso Celso de Assis. Porque me ufano de meu país. Rio de Janeiro:TypographiaUniversal de Laemmert, 1901.

IHERING Hermann Von. Adevastação e conservação das mattas. Revista do Museu Paulista, n.8, p.485-505, 1911.

LÓEFGREN, Alberto. Contribuições para a questão florestal da Região Nordeste do Brasil . 2. ed. Brasília: Ministério da Viação e Obras Públicas, 1923. (Investigações Botânicas, 18).

. Notas botânicas-Ceará. Rio Grande do Norte: Centro de Estudos e Debates Café Filho; Fundação Guimarães Duque, 1982.

MARSON,Adalberto. A trajetória de um republicano (Alberto Torres). Revista de História, v.52, n.103, p.501-518, 1975.

PEREIRA, OsnyDuarte. Direito florestal brasileiro. Rio de Janeiro: Borsoi, 1950.

RECLUS, Elisée. Estados Unidos do Brazil. Geographia, ethnographia, estatistica. Rio de Janeiro: B.L. Garnier, 1900.

SAMPAIO, Alberto José de. Pela conservação e renovação das mattas indigenas. Chácaras e Quintais, n.5, p.3-5, mar. 1912.

O problema florestal no Brasil, em 1926. Archivos do Museu Nacional. Rio de Janeiro, 1926, v. 28, dez. 1926.

.As florestas brasileiras. Boletim do Museu Nacional. Rio de Janeiro, v.4,

A destruição da natureza e os arautos... 
n.2, p.15-30, jun.1928.

Clubes de amigos da natureza nas escolas primárias. Revista Nacional de Educação,n.13-4, p.45-47, 1933.

. Biogeographia dynamica. Anatureza e o homemno Brasil. São Paulo: Companhia Editora Nacional, 1935. (Brasliana, 52).

. Reflorestamento e arborização. Conceitos fitogeográfico e agronômico em confronto. Boletim Geográfico, n.77, p.627-632, ago.1949.

TORRES, Alberto O problema nacional brasileiro. Introdução a umprograma de organização nacional. Rio de Janeiro: Imprensa Nacional, 1914.

. Asfontes de vida no Brasil. Rio de Janeiro: Papelaria Brazil, 1915.

.Aorganização nacional. São Paulo: CompanhiaEditora Nacional, 1933.

(Brasiliana, 27).

VASCONCELOS SOBRINHO, José de. Estudos e observações sobre as mattas de Pernambuco. Fronteiras, 1937, (Separata, n. 23).

Title:

THE DESTRUCTION OF NATURE AND THE HERALDS OF BRAZILIAN CONSERVACIONISM IN THE FIRST DECADES OF THE TWENTIETH CENTURY.

\section{Abstract:}

This paper aims to present the panorama of the destruction of nature in Brazil during the first decades of twentieth century, and the exponents of Brazilian conservacionism, that positioned themselves against that scenery of carelessness, ignorance and omission. The role and the actions of the main heralds of the struggle against the destruction that was infringed to the natural world are analyzed, specially the relevance of their ideas. Moreover, the first legal measures of the nature conservation in the last century are pointed out.

Keywords: Conservacionism, Destruction of Nature, Brazil, Forests, Twentieth Century. 